\title{
Neonatal Birth Injuries: An Orthopedic Clinic Presentation
}

\author{
Onuoha $\mathrm{KM}^{1 *}$, Omotola $\mathrm{OE}^{2}$, Orimolade $\mathrm{EA}^{2}$, Sotunsa $\mathrm{JO}^{3}$, Alade $\mathrm{OA}^{3}$ and 0 wolabi $\mathrm{IJ}^{3}$ \\ ${ }^{1}$ Department of Orthopaedics and Traumatology, Babcock University Teaching Hospital, Nigeria \\ ${ }^{2}$ Orthopaedic and Trauma Surgery Department, Obafemi Awolowo University Teaching Hospital, Nigeria \\ ${ }^{3}$ Department of Orthopaedic Surgery, Federal Medical Centre Abeokuta, Nigeria
}

*Corresponding author: Onuoha KM, Department of Orthopedics and Traumatology, Babcock University Teaching Hospital, Nigeria.

To Cite This Article: Onuoha KM, Neonatal Birth Injuries: An Orthopedic Clinic Presentation. 2020 - 7(6). AJBSR.MS.ID.001210.

DOI: 10.34297/AJBSR.2020.07.001210.

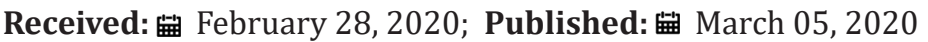

\section{Introduction}

Birth trauma is defined as injury sustained by the neonate during the process of labour and delivery. The incidence in the united states is 29 per 1000 births [1]. With the improvement in obstetric care and reduction in perinatal mortality and birth asphyxia, there is a rising trend in the incidence of birth trauma [2]. Some birth injuries occurred more frequently than others. While minor ones usually heal without major intervention, the major ones are often referred. Certain factors such as birth weight, parity, prolonged labour, mode of delivery, fetal presentation and facility where baby was delivered are possible etiologic factors. The aim of this study is to determine the pattern of neonatal birth injuries presenting in a typical orthopedic clinic in a Nigerian hospital and the possible associated factors.

\section{Methodology}

A prospective, hospital based cross sectional study carried out over a 2year period in a specialist Hospital, 46 neonates presenting to the Orthopedic clinic from July 2014 to June 2016 with birth injuries were assessed and data collection done using interviewer based semi-structured questionnaires. Statistical analysis was done using simple frequencies and chi-squared test for association. Patients were managed and followed up.

\section{Results}

During the study period, a total of 46 babies with birth injuries and their mothers were recruited in the Orthopaedic Clinic. Table 1 revealed majority $69.6 \%$ of the mothers were in their third decade of life (20-29years). There were $23.9 \%$ who were in the ages of $31-40$, while $6.5 \%$ of the mothers were older than 40 years. This is expected for the normal population as studies have shown that the usual age range for primigravida is 20-30 years [3]. The age range for the female reproductive age group is 15-49 years [4]. The table revealed that $67.4 \%$ of the babies with birth injuries were males while $32.6 \%$ were females. Studies have shown that there is a slight preponderance of males (52\%) compared to females in the population [5]. As regards baby's weight, the highest percentage $(39.1 \%)$ of babies with birth injuries have birth weight between $3.1-3.5 \mathrm{~kg}$, followed by babies with birth weight between $3.6-4.0 \mathrm{~kg}$ which account for $21.7 \%$. Also $19.6 \%$ of the babies were macrocosmic. While $50 \%$ have birth weight $\geq 3.6 \mathrm{~kg}$. Only $2.2 \%$ have low birth weight. This suggests that most of the babies at the time of delivery had normal weights with few exceptions and this correlates with other studies [6]. This suggests that birth injuries may occur in normal term neonates with normal birthweight and not just fetal macrosomia as it is always alleged that big babies have a hard time passing through the birth canal thus predisposing them to birth injuries [7]. As regards hospital/facility of delivery, the table shows that majority $(67.4 \%)$ delivered at tertiary hospitals, while $8.7 \%$, $10.9 \%$ and $13.0 \%$ were delivered at Primary health care centers, General hospitals and Private hospitals respectively. In a study done in Uganda, it was noted that women tend to deliver in the homes or worship centers once they confirm the baby is normal [8]. This however is not the case in this study, this observation is due to the free maternal and child health care of the State government at the Mother and child hospitals where pregnant women in the state and neighboring towns prefer to have their deliveries with resultant high Volume of deliveries. It's expected that despite the facilities and skill present in the tertiary hospitals, the birth injuries will reduce, however this is not the case. The total numbers of deliveries from the tertiary centers were equally high due to free delivery at 
the center. In a study done in Canada in 2009, it was noted that planned home births that were supervised by registered midwives had low rates of brachial plexus injury similar to those attended by physicians in tertiary centers [9].

\begin{tabular}{|c|c|c|c|}
\hline Survey Items & Classification & Frequency & Percentage \\
\hline \multirow{4}{*}{ Mother's Age } & $20-30$ & 32 & 69.6 \\
\hline & $31-40$ & 11 & 23.9 \\
\hline & $>40$ & 3 & 6.5 \\
\hline & Total & 46 & 100.0 \\
\hline \multirow{3}{*}{ Baby Gender } & Male & 31 & 67.4 \\
\hline & Female & 15 & 32.6 \\
\hline & Total & 46 & 100.0 \\
\hline \multirow{7}{*}{ Birth Weight } & $<2.0$ & 1 & 2.2 \\
\hline & $2.1-2.5$ & 4 & 8.7 \\
\hline & $2.6-3.0$ & 4 & 8.7 \\
\hline & $3.1-3.5$ & 18 & 39.1 \\
\hline & $3.6-4.0$ & 14 & 21.7 \\
\hline & $>4.0$ & 9 & 19.6 \\
\hline & Total & 46 & 100.0 \\
\hline \multirow[t]{5}{*}{ Hospital/facility of Delivery } & Primary health care Centre & 4 & 8.7 \\
\hline & General hospital & 5 & 10.9 \\
\hline & Private hospital & 6 & 13 \\
\hline & Tertiary hospital & 31 & 67.4 \\
\hline & Total & 46 & 100.0 \\
\hline \multirow{4}{*}{ Mode of Delivery } & SVD & 41 & 89.1 \\
\hline & Instrumental delivery & 3 & 6.5 \\
\hline & Caesarean section & 2 & 4.3 \\
\hline & Total & 46 & 100.0 \\
\hline \multirow{4}{*}{ EGA } & Term & 42 & 91.3 \\
\hline & Preterm & 2 & 4.3 \\
\hline & Post term & 2 & 4.3 \\
\hline & Total & 46 & 100 \\
\hline \multirow{6}{*}{ Parity } & Para $2+0$ & 32 & 69.6 \\
\hline & Para $3+0$ & 2 & 4.3 \\
\hline & Para $1+0$ & 8 & 17.4 \\
\hline & Para $2+1$ & 1 & 2.2 \\
\hline & Para $4+0$ & 3 & 6.5 \\
\hline & Total & 46 & 100.0 \\
\hline \multirow{3}{*}{ Pregnancy } & Singleton & 38 & 82.6 \\
\hline & Multiple & 8 & 17.4 \\
\hline & Total & 46 & 100.0 \\
\hline
\end{tabular}

With reference to mode of delivery, the table shows that more than two-thirds (89.1\%) delivered through SVD, while Instrumental delivery and Caesarean section accounted for $6.5 \%$ and $4.3 \%$ respectively. Vaginal delivery is still the commonest route of delivery even though the rate of Caesarian delivery has increased in the last decade worldwide [10]. Obstetrician tried to keep their rate of Caesarean delivery as low as possible with more difficult deliveries allowed vaginal delivery, this may increase the birth injuries from SVD thus making SVD a risk factor for birth injuries. Irrespective of the weight of the child, Caesarean deliveries tend to have less risk of birth injuries compared to vaginal deliveries. In this study, this is demonstrated $(\mathrm{X} 2=15.575, \mathrm{p}=0.016 \mathrm{df}=6)$ with $\alpha=0.05$ level of significance. Similar observations were reported in other studies [11]. Delivery by Caesarean section is 
carried out mostly by Obstetricians while delivery by SVD involves different categories of staff. Furthermore, delivery by Caesarean section is through a wider opening. With respect to their estimated gestational age (EGA), majority (91.3\%) were delivered at term. Only $4.3 \%$ were delivered preterm and $4.3 \%$ post term $(\mathrm{P}=0.45$, $\mathrm{x} 2=5.76, \mathrm{df}=6$ ). This suggests that the Gestational Age per se has little or no association with birth injuries, infact studies have shown that preterm delivery reduces the chances of birth trauma [12]. Hence the skill of the staff taking the deliveries, the weight of the baby and the decision about the route of delivery among other factors such as adequacy of the pelvic outlet may all be important considerations to reduce birth injuries.

Lastly, the table shows majority of the pregnancies were singleton (82.6\%) while multiple pregnancies accounted for $17.4 \%$. In this study, multiple pregnancies were not significantly associated with birth injuries. $(\mathrm{p}=0.7, \mathrm{x} 2=7.15, \mathrm{df}=3)$. This agrees with studies done by Kleinman et al however it reported increased risk of fetal death in multiple pregnancies [13]. The fetal presentation showed 93.5\% were cephalic while $6.3 \%$ where breech, $(\mathrm{P}=0.00, \mathrm{x} 2=22.1$, $\mathrm{df}=3$ ). Hence there is an association between fetal presentation and birth injuries. Cephalic presentations are considered normal and low risk in the absence of other risk factors and are often allowed deliveries with lower cadre of staff of birth attendants compared to breech presentation which is an independent high-risk factor for delivery. Breech presentations are managed by more skilled staff for vaginal delivery or considered for Caesarian section ab initio. If Breech delivery is handled by less skilled staff or birth attendants, they are likely to result in birth trauma, in this study, most of the deliveries were in a good Centre with adequate monitoring of highrisk pregnancies. Previous Studies shows that cephalic presentation is the commonest mode of presentation [14]. however, the risk of birth trauma is higher with abnormal presentations [15] (Table 2).

\begin{tabular}{|c|c|c|c|}
\hline Survey Items & Classification & Frequency & Percentage \\
\hline \multirow{3}{*}{ Second Stage prolonged or with some difficulties } & Yes & 17 & 37 \\
\hline & No & 29 & 63 \\
\hline & Total & 46 & 100 \\
\hline \multirow{3}{*}{ Fetal Presentation } & Cephalic & 43 & 93.5 \\
\hline & Breech & 3 & 6.5 \\
\hline & Total & 46 & 100 \\
\hline \multirow{3}{*}{ Birth Injuries Cephalohematoma } & Yes & 4 & 8.7 \\
\hline & No & 42 & 91.3 \\
\hline & Total & 46 & 100 \\
\hline \multirow{6}{*}{ Fractures and dislocations } & Clavicular & 15 & 32.6 \\
\hline & Femur & 5 & 10.9 \\
\hline & Humeral & 17 & 37 \\
\hline & Shoulder dislocation & 2 & 4.3 \\
\hline & Nil & 7 & 15.2 \\
\hline & Total & 46 & 100 \\
\hline \multirow{3}{*}{ Brachial plexus injuries } & Erbs palsy & 11 & 23.9 \\
\hline & Nil & 35 & 76.1 \\
\hline & Total & 46 & 100 \\
\hline Skin Injuries & Nil & 46 & 100 \\
\hline Other types of injuries & Nil & 46 & 100 \\
\hline \multirow{4}{*}{ Treatment given } & Observation & 13 & 28.3 \\
\hline & Splintage of Fractures & 22 & 47.8 \\
\hline & Physiotherapy & 11 & 23.9 \\
\hline & Total & 46 & 100 \\
\hline
\end{tabular}

Seventeen of the mothers (37\%) had prolonged second stage of labour ( $\mathrm{p}$ value of $0.4, \mathrm{x} 2=0.707, \mathrm{df}=1$ ). With reference to cephalohematoma, the table revealed that majority of patients presenting to our clinic (91.3\%) did not have cephalohematoma.
Minor Cephalohematoma and skin injuries are usually not referred at birth as they often will not require any special intervention. The four cases that presented were on account of size and delay in resorption. In order to accurately get the proportions of these 
injuries, screening at the point of birth in the labour ward or postnatal wards will better accurately document the proportion of these injuries. Some birth injuries will also be referred to other specialties such as severe subconjunctival hemorrhage to the ophthalmologists. Studies have shown that birth trauma has a higher risk of occurrence following prolonged labour which may manifest as cephalohematoma [14]. Thirty-Seven bone fractures were recorded with the highest percentage involving the Homarus (37.0\%) while clavicular fractures accounted for 32.6\%. Femoral fractures occurred only in $10.9 \%$. Majority of the Clavicular fractures presented due to swelling observed over the fracture sites one to 3 weeks post-delivery while the humeral and femoral shaft fractures presented within 24-48 hours of delivery. Two patients had Shoulder dislocations, one of which also had Erb's palsy and had been exposed to the traditional bone setter's manipulation for the Erb's palsy before presenting with the dislocation. With regards to Brachial plexus injuries, the table shows that $23.9 \%$ of patients presenting to the orthopedic Clinic had Erbs palsy. 2 patients suffered shoulder dislocation which was reduced. Studies done in the United States in 2010 revealed that the three most common birth injuries include cephalohematoma, injuries to the skeleton and clavicular fractures [1]. However, over the years, other studies have shown that clavicular fractures are the commonest injuries while facial nerve palsy has been seen in centers where instrumented delivery is frequent [16]. In this study the high proportion of humeral fractures presenting to the clinic may be due to the severity of this injuries which often necessitates immediate presentation to the Clinic while many Clavicular fractures go home undetected until swelling from callus formation occurs. Furthermore, our study was not conducted in the labour room where cases of cephalohematoma would have been identified. Not all clavicular fractures eventually present to the clinic for management and documentation unlike long bone fractures which are often more painful and cause deformities which result in early detection and early referral for management and documentation. In this study, the number of patients presenting to the Orthopedic Clinic with brachial plexus injuries did not reveal the true picture of this injury as many of the patients were referred to the physiotherapists directly for manipulation and muscle stimulation. Over the period of this study, the physiotherapy record revealed 39 new cases of Erb's Palsy patients with brachial plexus birth injuries. It is recommended that patients with brachial plexus injuries be referred first to the Orthopedic Surgeon who co-manages with the physical therapist as necessary. Many of the patients respond to simple manipulations without muscle or nerve stimulation. Treatment of Erb's palsy is multidisciplinary, requiring manipulation and casting, physiotherapy and possible surgery where indicated [17] (Table 3).

Table 3: Association between fractures sustained and some sociodemographic characteristics.

\begin{tabular}{|c|c|c|c|c|}
\hline Variables & X2 & Df & P value & Remark \\
\hline Gender \&Injuries & $5.908 \mathrm{a}$ & 3 & 0.823 & Insignificant \\
\hline Mode of delivery \&Injuries & $15.575 \mathrm{a}$ & 6 & 0.016 & Significant \\
\hline EGA\&Injuries & $5.768 \mathrm{a}$ & 6 & 0.45 & Insignificant \\
\hline Fetal presentation \& injuries. & $22.100 \mathrm{a}$ & 3 & 0.000 & Significant \\
\hline
\end{tabular}

\section{Conclusion}

Humeral and Clavicular Fractures are the commonest birth injuries presenting to the Orthopedic Clinic of a State Specialist Hospital. Erb's palsy is the commonest nerve injury often seen. Most of the injuries were seen in seemingly uncomplicated pregnancies with cephalic presentation and vaginal deliveries. Measures should be put in place to reduce the birth injuries following all pregnancies with an obvious need to reduce the prevalence of birth injuries in vaginal deliveries.

\section{Limitations}

Many Clavicular fractures are not detected at birth until the parents observe abnormal swelling during the phase of callous formation. Hence many of the patients may not present to the clinic as they are often painless at this stage. The study was carried out in the clinic and not the labour room where more cases of cephalohematoma would have been identified. The primary referral of many patients with Erb's palsy to the physical therapist affected information gathering on this injury and may have effects on data collected.

\section{References}

1. Sauber-scatzch EK, Markovic N, Bordna LM, Wilson JW, Pearlman MD (2010) Descriptive epidemiology of birth trauma in the United States in (2003). Paediatr Perinat Epidemiol 24(2): 116-124.

2. Cyr RM, Usher RH, Mclean FH (1984) Changing patterns of birth asphyxia and trauma over 20 years. Am J Obstet Gynecol 148(5): 490-498.

3. Benedict MI, Paine LL, Paine LA, Brandt D, Stallings R (1999) The association of childhood sexual abuse with depressive symptoms during pregnancy, and selected pregnancy outcomes. Child Abuse Negl 23(7): 659-670.

4. Nisar N, White F (2003) Factors affecting utilization of antenatal care among reproductive age group in an urban squatter settlement. J Pak Med Assoc 53(2): 47-53.

5. Noreen M, Eve R (1997) Sex Ratios: Are there natural variations within the human population? Obstetrics and Gynaecology 104(9): 1050-1053. 
6. Frederick IO, Williams MA, Sales AE, Martin DP, Killien M (2008) Prepregnancy Body Mass Index, Gestational weight Gain and other Maternal Characteristics in Relation to Infant Birth Weight. Matern Child Health J 12(5): 557-567.

7. Boulet SL, Alexander GR, Salihu HM, Pass M (2003) Macrosomic births in the united states: Determinants, outcomes and proposed grades of risk. Am J Obstet Gynecol 188(5): 1372-1378.

8. Amooti-Kaguna, Nuwaha F (2000) Factors influencing choice of delivery sitesin Rakai district of Uganda. Soc Sci Med 50(2): 203-213.

9. Janssen PA, Saxell L, Page LA, Klein MC, Liston RM, et al. (2009) Outcome of planned home birth with registered midwife versus planned hospital birth with midwife or physician. CMAJ 181(10): 6-7.

10. Mac Dorman MF, Menacker F, Declerq E, Caeserian (2008) Birth in the United states: Epidemiology, Trends and Outcomes. Clin Perinatol 35(2): 293-307.

11. Gudmunsson S, Henningsson AC, Lindqvist P (2005) Correlation of Birth Injury with Maternal height and birthweight. BJOG 112(6): 764-767.
12. Michael WH (1986) Ultrasound differentiation of the competent from the incompetent cervix: prevention of preterm delivery. American Journal of Obstertrics and Gynaecology 154(3): 537-546.

13. Kleinman JC, Fowler MG, Kessel S (1991) Comparison of Infant Mortality among Twins and Singletons. American Journal of Epidemiology 133(2): 133-143.

14. Levine MG, Holroyde J, Woods JR, Siddiqi TA, Scott M, et al. (1984) Birth Trauma: Incidence and predisposing factors. Obstet Gynecol 63(6):792795.

15. Gordon M, Rich H, Deutchberger J, Green M (1973) The immediate and long-term outcome of obstetric trauma: Brachial plexus paralysis. Am J Obstet Gynecol 117(1): 51-56.

16. Rubin A (1964) Birth Injuries: Incidence, Mechanisms and End results. Obstet Gynecol 23(2): 218-221.

17. Waters PM (2005) Update on management of pediatric brachial plexus palsy. J Pediatr Orthop B 14(4): 233-244. 